\title{
Quality of Life and its associated factors amongst Patients with Brain Tumors at a Tertiary Care Hospital in Pakistan: An Analytical Cross-Sectional Study
}

Nida Zahid ( $\nabla$ nida.zahid@aku.edu )

Aga Khan University Hospital

Russell Seth Martin

Aga Khan University Hospital

Wajeeha Zahid

Aga Khan University Hospital

Iqbal Azam

Aga Khan University Hospital

Aneesa Hassan

Aga Khan University Hospital

Khabir Ahmad

Aga Khan University Hospital

Shireen Shehzad Bhamani

Aga Khan University Hospital

Adnan Abdul Jabbar

Aga Khan University Hospital

Nargis Asas

Aga Khan University Hospital

Muhammad Shahzad Shamim

Aga Khan University Hospital

Rashid Jooma Khan

Aga Khan University Hospital

Gohar Javed

Aga Khan University Hospital

Ehsan Bari

Aga Khan University Hospital

Syed Ather Enam

Aga Khan University Hospital 


\section{Research Article}

Keywords: Quality of Life, Resilience, Anxiety, Depression, Social Support, Developing Country, Brain Tumor

Posted Date: December 1st, 2021

DOI: https://doi.org/10.21203/rs.3.rs-1110031/v1

License: (c) (i) This work is licensed under a Creative Commons Attribution 4.0 International License. Read Full License 


\section{Abstract \\ Introduction}

Despite quality of life (QoL) being recognized as an important outcome in neuro-oncology, there is a lack of research from Pakistan where sociocultural differences may influence QoL. This study aimed to measure the QoL in patients with primary brain tumors (PBTs), and assess its association with mental health outcomes, resilience, and social support.

\section{Methods}

A cross-sectional survey was conducted among primary brain tumor patients. QoL was measured using European Organization for Research and Treatment of Cancer Quality of Life Questionnaire. Resilience was assessed by Wagnild and Young's Resilience Scale, mental health outcomes using Hospital Anxiety and Depression Scale, and social support using the Enriched Social Support Instrument.

\section{Results}

Our study included a total of 250 patients, with median age of 42 years (range 33-54 years). The mean global QoL of the sample was $75.73 \pm 14.9$. On multivariable linear regression, global QoL was inversely associated with no or low income, having hypertension (-5.77), currently using a urine catheter (-15.33), having low social support (-28.16) suffering from mild (-9.88) or symptomatic (-17.59) depression, or mild anxiety (-7.11), while resilience (0.28) demonstrated a significant positive association.

\section{Conclusion}

The quality of life of patients with primary brain tumors in Pakistan is a function of clinical factors such as comorbid disease and use of a urinary catheter, social factors such a family income and social support, and psychological factors such as mental illness and resilience. Our findings may be of use in the development of QoL-improving interventions within the sociocultural setting of Pakistan.

\section{Lay Summary}

Despite quality of life (QoL) being recognized as an increasingly important outcome in the management of patients with primary brain tumors, there is a lack of research from Pakistan. Findings related to QoL, and its associated psychosocial factors, are likely to differ in Pakistan, due to a unique economic, social, and cultural landscape

Our study finds that the QoL of patients with primary brain tumors in Pakistan dependent on clinical factors such as comorbid disease, economic factors, such a family income, social factors such as social 
support, and psychological factors such as mental illness and resilience.

Our findings are of relevance to the holistic management of patients with PBTs in Pakistan and can aid the development and integration of QoL-improving interventions into the routine care of patients with PBTs.

\section{Introduction}

Though malignant primary brain tumors (PBTs) are responsible for $2.7 \%$ of cancer deaths globally [1], both the incidence and mortality rate of PBTs are lower in developing countries [2]. In Pakistan, a South Asian lower-middle-income country, malignant PBTs comprise around 3.6-3.9\% of all malignancies, with a higher incidence and mortality rate in males $[3,4]$. Patients with PBTs often suffer from clinically significant psychological distress [5], the levels of which are higher than that experienced by patients suffering from most other types of malignancies [6].

Quality of life (QoL) is an increasingly important outcome in clinical neuro-oncology that holistically encompasses functionality and wellness in the psychosocial, emotional, and physical domains [7]. Most patients with PBTs face distress across these domains, due to factors such as physical disability and symptomatology, disfigurement, sensorimotor deficits, losses of individual freedoms, employment, and income, and social stigma [6]. Apart from the clinical and physical domains, existing literature suggests that QoL is majorly affected by psychosocial factors, including mental health, resilience, and social support. Mental health outcomes, particularly depression, correlate strongly with poorer QoL in patients with PBTs [8]. Resilience, which enables patients to maintain stable functionality throughout the disease course, may help protect against adverse mental health outcomes and improve QoL in patients with PBTs $[9,10]$. Similarly, social support is also associated with better QoL $[11,12]$.

Although QoL of patients with PBTs has been a subject of global interest since the late 20th century [13], there is a notable lack research from Pakistan to date [10]. Findings related to QoL, and its associated psychosocial factors, are likely to differ in Pakistan, due to a unique economic, social, and cultural landscape [10]. As survivorship of patients with PBTs increases as a function of rapidly evolving therapies, QoL is being increasingly measured as an additional endpoint alongside traditional clinical outcomes in disease management and clinical trials [14]. There is an acutely increasing need to assess the QoL experienced by patients with PBT in Pakistan using widely accepted standardized tools. The EORTC QLQ-C30 (European Organization for Research and Treatment of Cancer Quality of Life Questionnaire) and its brain tumor-specific module EORTC QLQ-BN20 (EORTC QLQ-Brain Neoplasms 20) have proved to be brief, reliable, and valid assessment measures in this regard $[15,16]$. Thus, this study aimed to measure the quality of life in patients with PBT in Pakistan, and assess its association with mental health outcomes, resilience, and social support.

\section{Materials And Methods}




\section{Study Design and Setting}

This cross-sectional study was conducted at the Aga Khan University Hospital (AKUH), from November 2019 to May 2020. The AKUH is a Joint Commission International Accreditation (JCIA-accredited) notfor-profit private sector hospital, in Karachi, Pakistan. AKUH serves as a major quaternary care hospital in Karachi and the surrounding regions in the province of Sindh. The protocol of this study has been approved by the institutional review board at AKUH (Reference Number: 5154-Sur-ERC-17) and is published by the authors with reporting in accordance with the STROBE statement [10].

\section{Study Participants}

We recruited all adult ( $\geq 18$ years) patients treated for brain cancer at $A K U H$, provided that they gave informed consent and were currently $\geq 4$ weeks post-initiation of treatment. Furthermore, we only considered patients who had been living in Pakistan for at least the past 3 months, as we wished to investigate the relationship of social support in the context of Pakistan with QoL. Patients residing abroad could possibly be accustomed to sociocultural environments that differ to those experienced by patients in Pakistan, which may in turn affect their social support. In addition, patients with any known psychiatric history or on psychiatric medications, or with debilitating concurrent illnesses such as kidney failure or stroke, were excluded. However, patients were not excluded if they had hypertension, type 2 diabetes mellitus or cardiovascular disease, As the prevalence of these co-morbids is relatively high in Pakistan, including in patients with brain cancer [17], excluding patients on the basis of these comorbids would have led to a non-representative sample and hindered minimum sample size achievability.

\section{Sampling Technique}

A minimum sample size of 250 was calculated using the one population mean formula, a standard deviation of 20 , a $5 \%$ level of significance with precision of 2.5 , and by inflating by $10 \%$ to account for incomplete responses. Nonprobability consecutive sampling was employed to recruit patients. Members of the research team screened all patients with brain cancer who were presenting to the neurosurgery or oncology clinics at AKUH for their scheduled appointment. If deemed eligible, patients were thoroughly briefed regarding the study and then requested for informed consent for participation. If patients agreed, they were administered the survey questionnaire by the data collector.

\section{Data Collection Tools}

The final questionnaire consisted of the following components:

- Sociodemographic and Clinical Characteristics: Participants' sociodemographic details were recorded, with monthly household income reported in both Pakistani rupees (PKR) and United States dollars (US\$). Patients' role in their family, with regards to decision-making, was also recorded. Clinical data included tumor type, and type of surgical intervention and adjuvant therapy, if any.

- EORTC QLQ-C30: This 30-item QOL measure for patients with cancer. It comprises five functional scales (physical, role, cognitive, emotional, and social), three symptom scales (fatigue, pain, and 
nausea and vomiting), a global QOL scale, and single items for measurement of other symptoms frequently experienced by cancer patients, in addition to the perceived financial impact of the disease and treatment [15]. All items are scored using a 4-point Likert scale (1: 'not at all'; to 4: 'very much'), except for two items in the global QOL scale which instead employ modified 7- point linear analog scales. The functioning and global QOL subscales are scored ranging from 0 to 100 , where higher scores imply favorable conditions. However, while symptom subscales are also scored ranging from 0 to 100 , higher scores in these subscales imply greater symptoms i.e., unfavorable conditions.

- EORTC QLQ-BN20: This 20-item QOL measure is specifically for patients with primary brain neoplasms [16], and comprises four domains relevant to the disease (future uncertainty, visual disorder, motor dysfunction, and communication deficit), in addition to seven single items. All items are scored using a 4-point Likert scale (1: 'not at all'; to 4: 'very much') and are then linearly converted to a 0-100 scale, where a higher score implies unfavorable conditions.

The translation and in-depth validation of the EORTC QLQ-C30 and BN20 in Urdu has been performed by the authors in accordance with the EORTC guidelines. [18] The Urdu versions of both tools demonstrated sufficient validity for the measurement of QoL in patients with brain tumors in Pakistan. In our sample, the EORTC QLQ-C30 had a Cronbach alpha of 0.860 , and content validity index (CVI) scores for clarity and relevance of 0.98 and 0.96 . Similarly, the EORTC QLQ-BN20 had a Cronbach's alpha of 0.880 and CVI scores for clarity and relevance of 0.81 and 0.95 , respectively.[19]

- Resilience: The 14 item version of Wagnild and Young's Resilience Scale (RS14) uses a 7-point Likert Scale to calculate an aggregate score for resilience [20]. The higher the score on the RS-14, the higher the resilience. The Urdu version has been validated previously [21] and demonstrated excellent internal consistency in the current population as well (Cronbach's alpha of 0.903).

- Psychosocial Characteristics: The Hospital Anxiety and Depression Scale (HADS), a 14-item tool using a 4-point ordinal scale, was used to measure patients' depression and anxiety [10]. Patients' social support was evaluated using the Enriched Social Support Instrument (ESSI) [10]. For depression and anxiety, the score obtained on HADS, was categorized as follows: 0-7 (Normal); 810 (Mild Depression/Anxiety); and 11-21 (Symptomatic Depression/ Anxiety). A score $\leq 18$ on the ESSI was classified as Low Social Support, and $>18$ as High Social Support. The Urdu translations of both the HADS [22] and ESSI (CVI for relevance and clarity of 0.95 and 0.97 respectively; and Cronbach's alpha 0.8246) [23] were used.

The final Urdu questionnaire was pretested on $10 \%$ of the sample size to elucidate any ambiguities. However, no major changes were needed on the basis of the pretest.

\section{Statistical Analysis}

The data was analyzed using STATA version 15. Continuous variables were reported as mean and standard deviation (SD) or median and range, while categorical variables were reported as frequency and percentages. The means and standard deviations of the QoL scales were calculated according to the EORTC QLQ-C30 manual. General linear model (GLM) multivariate analysis of variance (MANOVA) was 
used to determine the association between independent factors and the QLQ-C30 and BN20 scales. The GLM-MANOVA approach is used to test the association between interrelated dependent variables (QoL

scales) and independent variables. The independent variables considered were demographics (age, gender, monthly income, and working status), comorbids (HTN, T2DM, and CVD), use of addictive substances (tobacco and alcohol), family history of cancer, tumor and treatment related factors (type of tumor, type of surgical intervention, and adjuvant therapy), social support, resilience and depression, and anxiety. Variables with a p-value $<0.20$ on the one-factor models were entered into the multi-factor model.

Linear regression was used to determine the factors associated with global QoL, and unadjusted and adjusted beta coefficients, standard error (SE), and 95\% confidence interval (CI) were reported. All plausible interactions were assessed, including household monthly income and social support, while also considering all aforementioned independent variables. Variables with a p-value $<0.25$ on univariate models were included in the multivariable linear regression model. A p-value $<0.05$ was considered significant for all analyses.

\section{Results}

\section{Study Participants}

Our study included a total of 250 patients, with median age of 42 years (range 33-54 years) and 169/250 $(67.6 \%)$ males. The vast majority $(91.6 \%)$ had received a formal education. Urdu was the most common mother-tongue (30.8\%), with Sindhi (18.8\%) and Punjabi (14.8\%) being others. Most patients (82\%) were married, and around half of them (54\%) lived in extended families. About one-third (30.8\%) of patients reported being their family's head/chief decision-makers. However, half $(50.8 \%)$ of patients were not currently working, and two-thirds $(66.8 \%)$ had non-working spouses. The median monthly household income was PKR 60000 (30000-100000)/USD 374 (187-623). The patients' sociodemographic characteristics are shown in Table 1 of the previous publication by the authors based on analysis of the same sample [24].

\section{Participants' Medical History and Tumor Characteristics}

Hypertension (HTN: 24\%) and type 2 diabetes mellitus (T2DM: 14.8\%) were the most common comorbids, while $6 \%$ of patients currently smoked and $2.8 \%$ currently used smokeless tobacco. The commonest brain tumors were glioma (46.8\%), meningioma (21.2\%), and schwannoma (4.8\%). Most patients underwent only a biopsy (78\%), while $4.4 \%$ underwent total resection only. Adjuvant therapy was received $39.2 \%$ of patients. Around half (55.2\%) of patients were still receiving treatment for their brain tumor, while the rest had completed treatment (Table 1). A family history of brain or other cancers were reported by $4.8 \%$ and $16 \%$ of patients, respectively, and only $4 \%$ of patients reported a family history of depression.

\section{Resilience, Social Support, and Mental Health}


Most patients reported high social support (97.6\%) and normal depression (90\%) and anxiety (91.6\%) scores. The mean resilience was $83.71 \pm 9.32$, which is categorized as high (Table 2).

\section{Quality of Life}

The mean global QoL score was 75.73. The values of the five functioning scales ranged from 81.2 (role functioning) to 87.93 (social functioning). In the symptom scales, pain had the highest score (29.7), followed by appetite loss (26.13), insomnia (25.06), and financial difficulties (21.06). The two worst symptoms on the BN-20 symptom scale were headache (21.46) and weakness (18.40). These are detailed in Table 3.

\section{Variables associated with QoL outcomes}

In the first step of the GLM-MANOVA, the association between the independent variables (detailed in Methods: Statistical Analysis) and the dependent variables (15 scales of QLQ-C30) was investigated (one-factor model). On the one-factor model, 17 variables were associated with the overall outcome of QLQ-C30 with $p<0.20$. These 17 variables were entered into the multifactor model analysis. Variables significantly associated on the multifactor model were age, type of intervention, adjuvant therapy, use of feeding tube, use of a urine catheter, resilience, depression, anxiety and social support (all $p<0.05)$. In the one-factor model with QLQ-BN20 as the outcome, 17 variables were associated with the overall outcome on QLQ-BN20 at $p<0.20$. In the multifactor model, role in family, smoking, smokeless tobacco use, family history of cancer other than brain, resilience, depression, anxiety and social support remained significantly associated $(p<0.05)$. Results of the GLM-MANOVA are shown in Table 4.

\section{Linear Regression Analysis}

On univariate linear regression with global QoL as the dependent variable, no formal schooling (Beta Coefficient: -8.59), no household income (-9.06) or PKR 6000-25,000 (-11.77), hypertension (-5.35), current use of smokeless tobacco (-15.12), current use of a urine catheter (-22.85), low social support (-14.98), mild $(-18.40)$ or symptomatic (-26.41) depression, and mild (-20.03) or symptomatic (-15.6) anxiety, were significantly negatively associated with QoL. Only resilience (0.67) was significantly positively associated with QoL. Age, T2DM, and status of cancer treatment demonstrated a p-value $<0.25$ on univariate analysis and were thus included in the multivariable model.

On multivariable linear regression, having no income (-10.96), an income of PKR 6000-25,000 (-10.42) or PKR 25,000-40,000 (-7.82), having hypertension (-5.77), and currently using a urine catheter (-15.33) were significantly negatively associated with global QoL. Having low social support (-28.16) was also inversely associated with global QoL, while resilience ( 0.28$)$ demonstrated a significant positive association. In addition, suffering from mild (-9.88) or symptomatic (-17.59) depression, or mild anxiety (-7.11), was also associated with a poorer QoL (Table 5).

\section{Discussion}


Patients with PBTs suffer considerable physical, cognitive, and emotional distress due to their disease course, which negatively impacts their QoL. Our study is the first to explore factors associated with QoL in patients with PBTs in Pakistan and provide a much-needed perspective on this increasingly important outcome of cancer management within the sociocultural setting of a LMIC.

In our study, the mean global QoL (75.73) and scores on the five functional subscales (81.20-87.93) as measured by the EORTC QLQ-C30 are higher than a global weighted mean calculated using data from Austria, Germany, France, Turkey, Canada, The Netherlands, Iran and India [25]. In addition, all symptom components on the QLQ-BN20 were lower in our study, barring weakness of legs (mean of $18.40 \pm 25.33$ in our study vs. weighted mean $17.72 \pm 92.99$ ) [25]. It is possible that these findings of an overall better QoL in our sample are a function of the higher resilience and social support, and lower depression and anxiety, which contribute towards better QoL [21]. The higher social support, in turn, is likely due to the close-knit extended family systems that are a feature of South Asian households (54\% of patients in our study lived in extended families). However, our study reported higher scores than the global weighted mean on 5/9 of the symptom scales on the QLQ-C30 (pain, insomnia, appetite loss, diarrhea, and financial difficulties). An interesting theory is that since the population of a developing country like Pakistan is generally accustomed to a lower standard of living and QoL than that of a developed country, the drop in QoL due to an illness may be perceived as less significant despite similar or worse symptomatology. Interestingly, the male predominance and median age of 42 years (range 33-54 years) represents the demographic that encompasses the breadwinners of most Pakistani families, which could explain the greater financial difficulties in our sample.

The results of multivariable linear regression in our study revealed comorbid hypertension, use of a urine catheter, lower family income, low social support, and coexisting anxiety and depression to be associated with a poorer global QoL, while higher resilience scores was associated with a better global QoL. These findings are self-explanatory and supported by previous literature. Hypertension, chronic need for a urinary catheter, and low socioeconomic status are known to be independently associated with poorer quality of life [26-28]. Greater social support and resilience [29] have been found to be associated with better QoL in patients with PBTs $[12,30]$, while poorer mental health, particularly anxiety and depression, is associated with worse QoL [31]. Our findings are of relevance to the holistic management of patients with PBTs in Pakistan and can aid the development and integration of QoL-improving interventions into the routine care of patients with PBTs. In addition, our results also make the case for periodic screening of patients with PBTs for adverse mental health outcomes, so that these may be identified and treated early, and their harmful impact on QoL be negated.

As AKUH is one of the largest quaternary care hospitals in the largest city of Pakistan, the sample recruited in our study was representative of all major ethnicities and economic classes in the country, which boosts the generalizability of our findings. In addition, the Urdu translations of the tools used in this study were all sufficiently validated in a Pakistani population. Importantly, patients identified as symptomatic for anxiety or depression were referred to a psychiatrist, whereas those who were mildly anxious or depressed were provided with on-spot counseling by a trained psychologist. Lastly, as this was 
a cross-sectional study, we were unable to draw conclusions with regards to the temporal relationship between QoL and associated psychological factors such as depression, anxiety, and resilience.

\section{Conclusions}

The quality of life of patients with primary brain tumors in Pakistan is a function of clinical factors such as comorbid disease and use of a urinary catheter, social factors such a family income and social support, and psychological factors such as mental illness and resilience. Our findings may be of use in the development of QoL-improving interventions within the sociocultural setting of Pakistan.

\section{Abbreviations}

QoL Quality of Life

PBT Primary Brain tumor

EORTC QLQ- European Organization for Research and Treatment of Cancer Quality of Life C30 Questionnaire Core 30

EORTC QLQ- European Organization for Research and Treatment of Cancer Quality of Life BN20 Questionnaire Brain Neoplasms 20

\begin{tabular}{ll} 
AKUH & Aga Khan University Hosp \\
\hline PKR & Pakistani Rupees \\
\hline CVI & Content validation Index \\
\hline RS & Resilience Score \\
\hline HADs & Hospital anxiety and depr \\
\hline ESSI & Enriched Social Support I \\
\hline SD & Standard Deviation \\
\hline GLM & General linear model multiv \\
MANOVA & \\
\hline HTN & Hypertension \\
\hline T2DM & Type2 Diabetes Mellitus \\
\hline CVD & Cardiovascular Disease \\
\hline SE & Standard error \\
\hline CI & Confidence Interval \\
\hline
\end{tabular}

\section{Declarations}


Ethics approval and consent to participate: Ethics approval was sorted from Aga University Ethical Review Committee ERC \#5154-Sur-ERC-17 and informed written consent was

Consent for publication: Consent for publication was obtained from the study participants

Availability of data and materials: The datasets used and/or analysed during the current study are available from the corresponding author on reasonable request.

Competing interests: The authors declare that they have no competing interests.

Funding: The work is funded by Aga Khan University's SEED Money grant Award Number PF 89-1016 and the funders had no role in study design and development of proposal

Authors' contributions: NZ conceived the study, analyzed data, and critically reviewed the manuscript. RSM drafted, revised, and critically reviewed the manuscript. WZ and IA contributed to data analysis and critically reviewed the manuscript. $\mathrm{AH}, \mathrm{KA}, \mathrm{SSB}$, and NA overlooked the study and intellectually contributed to the manuscript. AAJ, MSS, RJK, GJ, EB and SAE were the subject experts and contributed to the design of the study. All authors have contributed intellectually to this manuscript and have read and approved the final manuscript

Acknowledgements: The authors would like to acknowledge the research associate Barka Raj and secretarial support Mirza Anas. We are grateful to Wagnild for giving us permission to use the RS-14 and to EORTC for allowing us to use EORTC QLQ-C30 and QLQ-BN20.

\section{References}

1. Siegel RL, Miller KD, Jemal A: Cancer statistics, 2016. CA: a cancer journal for clinicians 2016, 66(1):7-30.

2. Bondy ML, Scheurer ME, Malmer B, Barnholtz-Sloan JS, Davis FG, II'yasova D, Kruchko C, McCarthy BJ, Rajaraman P, Schwartzbaum JA et al: Brain tumor epidemiology: consensus from the Brain Tumor Epidemiology Consortium. Cancer 2008, 113(7 Suppl):1953-1968.

3. Ahmad Z, Idress R, Fatima S, Uddin N, Ahmed A, Minhas K, Memon A, Fatima SS, Arif M, Hasan SH: Commonest cancers in Pakistan-findings and histopathological perspective from a premier surgical pathology center in Pakistan. Asian Pac J Cancer Prev 2016, 17(3):1061.

4. Sarwar MR, Saqib A: Cancer prevalence, incidence and mortality rates in Pakistan in 2012. Cogent Medicine 2017, 4(1):1288773.

5. Goebel S, Stark AM, Kaup L, von Harscher M, Mehdorn HM: Distress in patients with newly diagnosed brain tumours. Psycho-oncology 2011, 20(6):623-630.

6. Randazzo D, Peters KB: Psychosocial distress and its effects on the health-related quality of life of primary brain tumor patients. CNS Oncol 2016, 5(4):241-249. 
7. Liu R, Page M, Solheim K, Fox S, Chang SM: Quality of life in adults with brain tumors: current knowledge and future directions. Neuro Oncol 2009, 11(3):330-339.

8. Pelletier G, Verhoef MJ, Khatri N, Hagen N: Quality of life in brain tumor patients: the relative contributions of depression, fatigue, emotional distress, and existential issues. Journal of neurooncology 2002, 57(1):41-49.

9. Liang S-Y, Liu H-C, Lu Y-Y, Wu S-F, Chien C-H, Tsay S-L: The Influence of Resilience on the Coping Strategies in Patients with Primary Brain Tumors. Asian Nursing Research 2020, 14(1):50-55.

10. Zahid N, Khalid W, Ahmad K, Bhamani SS, Azam I, Asad N, Jabbar AA, Khan M, Enam A: Resilience and quality of life (QoL) of head and neck cancer and brain tumour survivors in Pakistan: an analytical cross-sectional study protocol. BMJ Open 2019, 9(9):e029084.

11. Zdun-Ryżewska A, Basiński K, Majkowicz M, Podolska M, Landowski J, Walden-Gałuszko K: Association between social support and quality of life in patients with affective disorders. The European Journal of Psychiatry 2018, 32(3):132-138.

12. Köhler M, Steinmann E, Maximilian Mehdorn H, Pedersen A, Goebel S: The importance of social relationships for brain tumor patients' quality of life: A case for the inclusion of the concept of disclosure in psycho-oncological care. Journal of psychosocial oncology 2020, 38(3):310-327.

13. Bampoe J, Ritvo P, Bernstein M: Quality of life in patients with brain tumor: what's relevant in our quest for therapeutic efficacy. Neurosurgical focus 1998, 4(6):E8.

14. Jalali R, Dutta D: Factors influencing quality of life in adult patients with primary brain tumors. Neuro-Oncology 2012, 14(suppl_4):iv8-iv16.

15. Aaronson NK, Ahmedzai S, Bergman B, Bullinger M, Cull A, Duez NJ, Filiberti A, Flechtner H, Fleishman SB, de Haes JC: The European Organization for Research and Treatment of Cancer QLQC30: a quality-of-life instrument for use in international clinical trials in oncology. JNCl: Journal of the National Cancer Institute 1993, 85(5):365-376.

16. Taphoorn MJ, Claassens L, Aaronson NK, Coens C, Mauer M, Osoba D, Stupp R, Mirimanoff RO, van den Bent MJ, Bottomley A: An international validation study of the EORTC brain cancer module (EORTC QLQ-BN20) for assessing health-related quality of life and symptoms in brain cancer patients. European Journal of Cancer 2010, 46(6):1033-1040.

17. Bergqvist J, Iderberg $\mathrm{H}$, Mesterton J, Bengtsson N, Wettermark B, Henriksson R: Healthcare resource use, comorbidity, treatment and clinical outcomes for patients with primary intracranial tumors: a Swedish population-based register study. Acta Oncologica 2017, 56(3):405-414.

18. Cull A, Sprangers M, Aaronson N: EORTC quality of life study group translation procedure (Internal report). Brussels: EORTC Quality of Life Study Group 1994.

19. Zahid N, Martins RS, Zahid W, Khalid W, Azam I, Bhamani SS, Asad N, Ahmad K, Jabbar AA, Shamim MS: Translation and validation of the Urdu version of the European organization for research and treatment of cancer core quality of life questionnaire (EORTC QLQ-C30) and brain module (QLQBN20) in primary brain tumor patients. Journal of patient-reported outcomes 2021, 5(1):1-12. 
20. Wagnild GM: The resilience scale user's guide: For the US English version of the Resilience Scale and the 14-item Resilience Scale (RS-14): Resilience center; 2011.

21. Zahid N, Martins RS, Zahid W, Khalid W, Azam I, Bhamani SS, Ahmad K, Jabbar A, Shamim MS, Khan $\mathrm{RJ}$ : Resilience and its associated factors in brain tumor patients in Karachi, Pakistan: An analytical cross-sectional study. Psycho-Oncology 2021, 30(6):882-891.

22. Mumford D, Tareen I, Bajwa M, Bhatti M, Karim R: The translation and evaluation of an Urdu version of the Hospital Anxiety and Depression Scale. Acta Psychiatrica Scandinavica 1991, 83(2):81-85.

23. Khalid W, Rozi S, Ali TS, Azam I, Mullen MT, Illyas S, Soomro N, Kamal AK: Quality of life after stroke in Pakistan. BMC neurology 2016, 16(1):1-12.

24. Zahid N, Martins RS, Zahid W, Khalid W, Azam I, Bhamani SS, Ahmad K, Jabbar A, Shamim MS, Khan $\mathrm{RJ}$ : Resilience and its associated factors in brain tumor patients in Karachi, Pakistan: An analytical cross-sectional study. Psycho-Oncology 2021.

25. Chiu L, Chiu N, Zeng L, Zhang L, Popovic M, Chow R, Lam H, Poon M, Chow E: Quality of life in patients with primary and metastatic brain cancer as reported in the literature using the EORTC QLQBN20 and QLQ-C30. Expert Review of Pharmacoeconomics \& Outcomes Research 2012, 12(6):831837.

26. Trevisol DJ, Moreira LB, Fuchs FD, Fuchs SC: Health-related quality of life is worse in individuals with hypertension under drug treatment: results of population-based study. Journal of Human Hypertension 2012, 26(6):374-380.

27. Abiola 00, Ogunwobi O, Oyeronke T, Ayeni S, Segun O: Quality of life and prevalence of depressive symptoms among patients on prolonged indwelling urinary catheters: A study from South west, Nigeria. International Journal of Medicine and Medical Sciences 2016, 8:96-104.

28. Zhang Y, Ou F, Gao S, Gao Q, Hu L, Liu Y: Effect of low income on health-related quality of life: a cross-sectional study in northeast China. Asia-Pacific journal of public health 2015, 27(2):NP10131025.

29. Pan C-J, Liu H-C, Liang S-Y, Liu C-Y, Wu W-W, Cheng S-F: Resilience and Coping Strategies Influencing the Quality of Life in Patients With Brain Tumor. Clinical Nursing Research 2017, 28(1):107-124.

30. Troschel FM, Ahndorf F, Wille L-M, Brandt R, Jost J, Rekowski S, Eich HT, Stummer W, Wiewrodt R, Jetschke K et al: Quality of Life in Brain Tumor Patients and Their Relatives Heavily Depends on Social Support Factors during the COVID-19 Pandemic. Cancers 2021, 13(6):1276.

31. Srivastava S, Bhatia MS, Gaur A, Singh G: Psychiatric and cognitive correlates of quality of life among persons with primary brain tumors. Ind Psychiatry J 2019, 28(1):141-147.

\section{Tables}




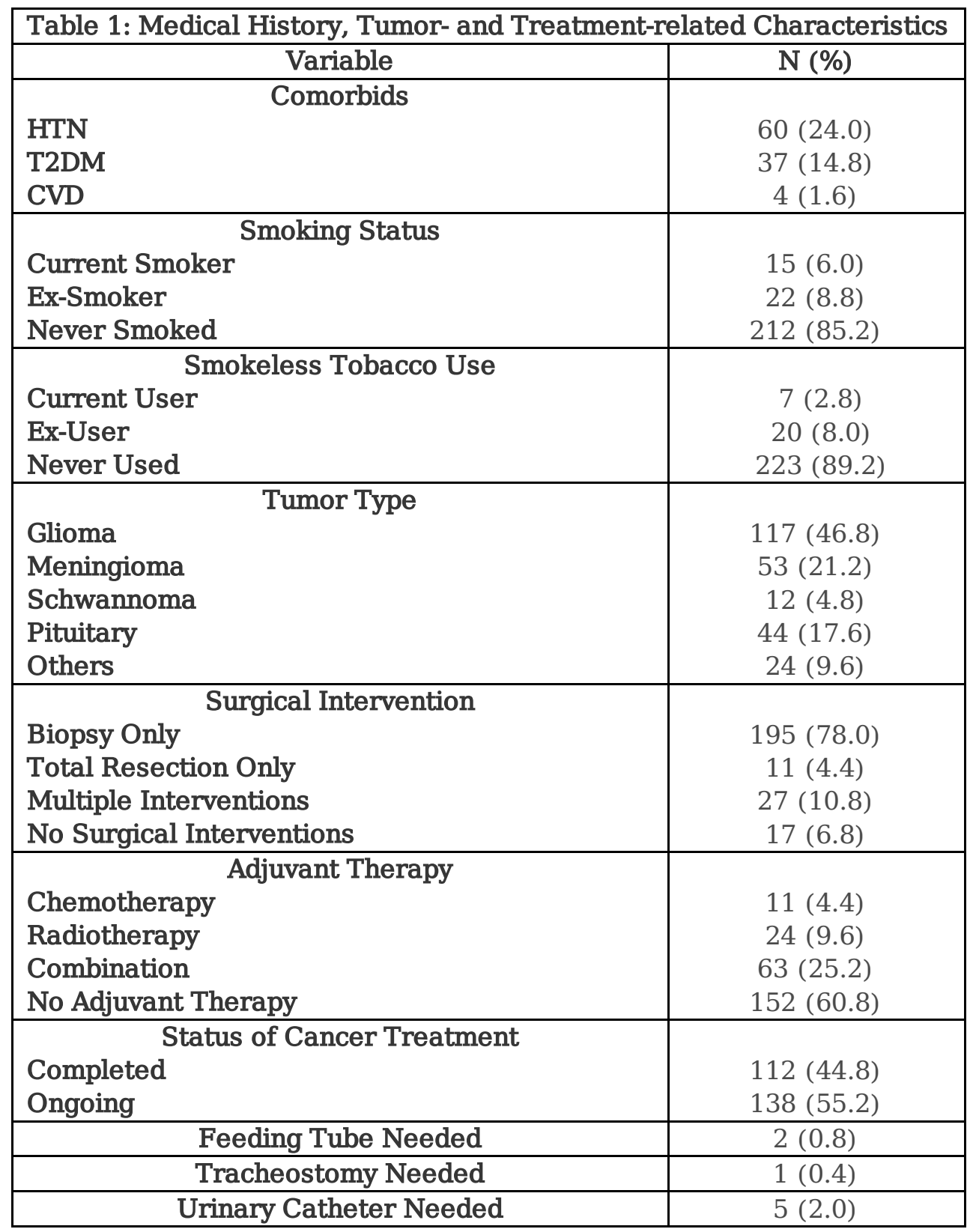




\begin{tabular}{|c|c|}
\hline Variable & $\mathbf{N}(\%) /$ Mean \pm SD \\
\hline Resilience & $83.71 \pm 9.32$ \\
\hline $\begin{array}{c}\text { Social Support } \\
\leq 18 \text { (Low Social Support) } \\
>18 \text { (High Social Support) }\end{array}$ & $\begin{array}{c}6(2.4) \\
244(97.6)\end{array}$ \\
\hline $\begin{array}{l}\text { Depression } \\
\text { 0-7 (Normal) } \\
\text { 8-10 (Mild Depression) } \\
\text { 11-21 (Symptomatic Depression) }\end{array}$ & $\begin{aligned} 225 & (90.0) \\
14 & (5.6) \\
11 & (4.4)\end{aligned}$ \\
\hline $\begin{array}{l}\text { Anxiety } \\
0-7 \text { (Normal) } \\
\text { 8-10 (Mild Anxiety) } \\
\text { 11-21 (Symptomatic Anxiety) }\end{array}$ & $\begin{array}{c}229(91.6) \\
16(6.4) \\
5(2.0)\end{array}$ \\
\hline
\end{tabular}

\begin{tabular}{|l|c|}
\hline \multicolumn{1}{|c|}{ Table 3: Quality of Life (QoL) of Brain Tumor Patients as measured by the EORCT QLQ-C30 and QL-BN20 } \\
\hline \multicolumn{1}{|c|}{ Global QoL } & Mean (SD) \\
\hline \multicolumn{1}{|c|}{ Functional Scale } & $75.73(14.9)$ \\
\hline Physical Functioning & $81.65(21.45)$ \\
\hline Role Functioning & $81.20(33.02)$ \\
\hline Emotional Functioning & $86.07(13.34)$ \\
\hline Cognitive Functional & $84.53(20.39)$ \\
\hline Social Functional & $87.93(21.01)$ \\
\hline & \\
\hline Fatigue & $9.55(11.95)$ \\
\hline Nausea & $9.20(15.00)$ \\
\hline Pain & $29.70(30.48)$ \\
\hline Dyspnea & $4.66(14.02)$ \\
\hline Insomnia & $25.06(25.40)$ \\
\hline Appetite Loss & $26.13(26.40)$ \\
\hline Constipation & $2.13(9.20)$ \\
\hline Diarrhea & $11.46(22.59)$ \\
\hline Financial Difficulties & $21.06(32.59)$ \\
\hline QLQ-BN20 Component & Mean (SD) \\
\hline Symptom Scale & \\
\hline Future Uncertainty & $7.53(14.32)$ \\
\hline Visual Disorder & $8.16(15.30)$ \\
\hline Motor Symptoms & $11.46(17.15)$ \\
\hline Communication Deficit & $9.33(16.38)$ \\
\hline Headache & $21.46(25.46)$ \\
\hline Seizures & $2.93(11.96)$ \\
\hline Drowsiness & $10.13(21.00)$ \\
\hline Hair Loss & $10.53(21.12)$ \\
\hline Itchy Skin & $7.33(17.27)$ \\
\hline Weakness & $18.40(25.33)$ \\
\hline Bladder Control & $5.86(17.45)$ \\
\hline
\end{tabular}




\begin{tabular}{|c|c|c|}
\hline \multirow{2}{*}{\multicolumn{3}{|c|}{$\begin{array}{l}\text { Table 4: Association of clinicodemographic variables with QLQ-C30 and B } \\
\text { GLM-MANOVA: General Linear Model Multivariate Analysis of Variance. } \\
* \mathrm{p} \text { value }<0.2 \text { by one factor model of GLM-MANOVA } \\
* * \mathrm{p} \text { value }<0.05 \text { by multifactor model of GLM-MANOVA } \\
\text { EORTC QLQ-C30 }\end{array}$}} \\
\hline & & \\
\hline Variables & $\begin{array}{l}\text { One factor Model } \\
\text { Wilk } \lambda \text { ( } p \text { value) }\end{array}$ & $\begin{array}{c}\text { Multifactor Model } \\
\text { Wilk } \lambda \text { ( } p \text { value) }\end{array}$ \\
\hline Age (years) & $0.84(<0.01) *$ & $0.81(<0.001)^{* *}$ \\
\hline Role in family & $0.86(0.19) *$ & NS \\
\hline Monthly household income & $0.56(<0.001) *$ & NS \\
\hline HTN & $0.91(0.11) *$ & NS \\
\hline T2DM & $0.88(<0.01)^{*}$ & NS \\
\hline CVD & $0.89(0.02) *$ & NS \\
\hline Smokeless Tobacco Use & $0.78(<0.001) *$ & NS \\
\hline Type of Tumor & $0.71(0.02) *$ & NS \\
\hline Treatment of cancer & $0.88(<0.01) *$ & NS \\
\hline Types of Intervention & $0.68(<0.001)^{*}$ & $0.72(0.002) * *$ \\
\hline Adjuvant therapy & $0.69(<0.001) *$ & $0.76(0.03) * *$ \\
\hline Feeding tube & $0.91(<0.001) *$ & $0.87(<0.01)^{* *}$ \\
\hline Urine Catheter & $0.82(0.07) *$ & $0.77(<0.001) * *$ \\
\hline Resilience & $0.54(<0.001) *$ & $0.72(<0.001) * *$ \\
\hline Depression & $0.52(<0.001) *$ & $0.74(<0.001) * *$ \\
\hline Anxiety & $0.57(<0.001) *$ & $0.64(<0.001) * *$ \\
\hline Social support & $0.79(<0.001) *$ & $0.83(0.001) * *$ \\
\hline \multicolumn{3}{|c|}{ EORTC QLQ-BN20 } \\
\hline Variables & $\begin{array}{l}\text { One factor Model } \\
\text { Wilk } \lambda \text { ( } p \text { value) }\end{array}$ & $\begin{array}{c}\text { Multifactor Model } \\
\text { Wilk } \lambda \text { ( } p \text { value) }\end{array}$ \\
\hline Role in family & $0.88(0.16) *$ & $0.84(0.01) * *$ \\
\hline Monthly Household Income & $0.76(0.03) *$ & NS \\
\hline T2DM & $0.91(0.03) *$ & NS \\
\hline CVD & $0.92(0.04) *$ & NS \\
\hline Smoking & $0.82(<0.01)^{*}$ & $0.78(<0.001) * *$ \\
\hline Smokeless tobacco use & $0.8(<0.001) *$ & $0.78(<0.001) * *$ \\
\hline Family history of Brain Tumor & $0.92(0.04) *$ & NS \\
\hline Family history of Other Cancer & $0.89(<0.001) *$ & $0.89(<0.01)^{* *}$ \\
\hline Type of Tumor & $0.71(<0.001) *$ & NS \\
\hline Status of Cancer Treatment & $0.9(<0.001) *$ & NS \\
\hline Types of Intervention & $0.82(0.07) *$ & NS \\
\hline Adjuvant therapy & $0.79(<0.001) *$ & NS \\
\hline Urine catheter & $0.91(0.02) *$ & NS \\
\hline Resilience & $0.54(<0.001) *$ & $0.66(<0.001) * *$ \\
\hline Depression & $0.57(<0.001) *$ & $0.73(<0.001)^{* *}$ \\
\hline Anxiety & $0.7(<0.001) *$ & $0.72(<0.001) * *$ \\
\hline Social support & $0.84(<0.001) *$ & $0.86(<0.001)^{* *}$ \\
\hline
\end{tabular}


Table 5: Univariate and multivariable linear regression with global QoL as dependent variable SE: standard error; CI: confidence interval

$* \mathrm{p}<0.25$ on univariable analysis

$* * \mathrm{p}<0.05$

\begin{tabular}{|c|c|c|}
\hline & Univariate Analysis & Multivariable Analysis \\
\hline Variables & Beta Coefficient (SE) $[95 \%$ CI] & Beta Coefficient (SE) $[95 \% \mathrm{CI}]$ \\
\hline Age (in years) & $-0.12(0.07)[-0.26,0.01] *$ & NS \\
\hline $\begin{array}{l}\text { Formal Schooling } \\
\text { Yes (Reference) } \\
\text { No }\end{array}$ & $\begin{array}{c}\text { Reference } \\
-8.59(3.36)[-15.22,-1.97] * *\end{array}$ & NS \\
\hline Monthly Family Income (PKR/USD) & & \\
\hline No Income & - $9.06(3.69)[-16.3,-1.78] * *$ & $-10.96(3.01)[-16.89,-5.03] * *$ \\
\hline $6000-25000 / 38-151$ & $-11.77(2.70)[-17.10,-0.64] * *$ & $-10.42(2.26)[-14.88,-5.95] * *$ \\
\hline $25000-40000 / 151-242$ & $-6.17(3.18)[-12.44,0.08]^{*}$ & $-7.82(2.637)[-13.01,-2.62] * *$ \\
\hline $40000-80000 / 242-484$ & $-3.56(2.26)[-8.03,0.90] *$ & $-3.45(1.869)[-7.14,0.22]$ \\
\hline 80000-1500000/484-1028 (Reference) & Reference & Reference \\
\hline $\begin{array}{c}\text { Hypertension } \\
\end{array}$ & $-5.35(2.18)[-9.66,-1.04] * *$ & $-5.77(1.75)[-9.22,-2.31] * *$ \\
\hline T2DM & $-4.56(2.64)[-9.77,0.65] *$ & NS \\
\hline $\begin{array}{l}\quad \text { Smokeless Tobacco Use } \\
\text { Current User } \\
\text { Ex-User } \\
\text { Never Used (Reference) } \\
\end{array}$ & $\begin{array}{c}-15.12(6.480)[-27.88,-2.35] * * \\
0.36(3.44)[-6.42,7.15] \\
\text { Reference } \\
\end{array}$ & NS \\
\hline $\begin{array}{l}\text { Status of Cancer Treatment } \\
\text { Complete (Reference) } \\
\text { Ongoing }\end{array}$ & $\begin{array}{c}\text { Reference } \\
-2.44(1.89)[-6.17,1.28] * \\
\end{array}$ & NS \\
\hline Using Urine Catheter & $-22.85(6.59)[-35.85,-9.87] * *$ & $-15.33(5.51)[-26.72,-8.52] * *$ \\
\hline $\begin{array}{l}\text { Social Support } \\
\leq 18 \text { (Low Social Support) } \\
>18 \text { (High Social Support) (Reference) }\end{array}$ & $\begin{array}{c}-14.98(6.10)[-27.00,-2.95] * * \\
\text { Reference }\end{array}$ & $\begin{array}{c}-28.16(13.35)[-1.84,-54.49] * * \\
\text { Reference }\end{array}$ \\
\hline $\begin{array}{c}\text { Resilience } \\
\end{array}$ & $0.67(0.09)[0.49,0.85] * *$ & $0.28(0.09)[0.09,0.48] * *$ \\
\hline $\begin{array}{l}\text { Depression } \\
\text { 0-7 (Normal) (Reference) } \\
\text { 8-10 (Mild Depression) } \\
\text { 11-21 (Symptomatic Depression) }\end{array}$ & $\begin{array}{c}\text { Reference } \\
-18.40(3.68)[-25.66,-11.14] * * \\
-26.41(4.13)[-34.54,-18.27] * *\end{array}$ & $\begin{array}{c}\text { Reference } \\
-9.88(3.68)[-17.15,-2.62)]^{* *} \\
-17.59(4.60)[-26.67,-8.52] * *\end{array}$ \\
\hline \begin{tabular}{l}
\multicolumn{1}{c}{ Anxiety } \\
0-7 (Normal) (Reference) \\
8-10 (Mild Anxiety) \\
11-21 (Symptomatic Anxiety) \\
\end{tabular} & $\begin{array}{c}\text { Reference } \\
-20.03(3.62)[-27.16,-12.90] * * \\
-15.6(6.32)[-28.12,-3.19]^{* *} \\
\end{array}$ & $\begin{array}{c}\text { Reference } \\
-7.11(2.35)[-18.90,-6.33] * * \\
-12.83(0.60)[-19.86,5.94] \\
\end{array}$ \\
\hline
\end{tabular}

